\title{
Sindicalismo, política y militancia de izquierda: reflexiones a partir de una experiencia de sindicalismo de base del sector automotriz en Argentina
}

\author{
Unionism, politics and left militancy: reflections from an experience of rank and \\ file unionism in the automotive sector in Argentina
}

\author{
Mariela Cambiasso* - Lucila D'Urso** - Julieta Longo***
}

Resumen: El objetivo del trabajo es abordar la relación entre sindicalismo y política a partir del análisis del caso de la autopartista Lear, una experiencia de sindicalismo de base en Argentina fuertemente atravesada por la conflictividad laboral. Nos preguntamos de qué modo se expresa la política en la cotidianeidad de la fábrica, cómo se articula el trabajo, la política y la acción sindical, y en qué medida la militancia de izquierda se plantea como un elemento externo (o no) al espacio de trabajo. Para ello, recurrimos a una metodología cualitativa, basada en el análisis de entrevistas en profundidad a delegados y activistas de la fábrica.

Palabras clave: Sindicalismo, política, militancia de izquierda, conflicto, automotriz.

\begin{abstract}
The porpose of the article is to address the relationship between unionism and politics analyzing Lear autopartist industry, an experience of rank and file unionism in Argentina strongly affected by labor conflictivity. We ask ourselves in what way politics is expressed in the daily life of the factory, how work, politics and union action are articulated, and in what mode the left militancy is presented as an external element (or not) to the workplace. For this, we resort to a qualitative methodology, based on the analysis of in-depth interviews to factory delegates and activists.
\end{abstract}

Keywords: Unionism, politics, left militancy, conflict, automotive sector.

Recibido: 16 marzo 2018 Aceptado: 30 mayo 2018

\footnotetext{
* Argentina, Co-autora. Doctora en Ciencias Sociales (UBA), Becaria Posdoctoral del CONICET con lugar de trabajo en el Centro de Estudios e Investigaciones Laborales (CEIL). Docente de la Carrera de Sociología de la Universidad de Buenos Aires. Mail: m_cambiasso@hotmail.com.

** Argentina, Co-autora. Doctora en Ciencias Sociales (UBA), Becaria Posdoctoral del CONICET con lugar de trabajo en el Centro de Innovación para los Trabajadores (CITRA). Docente de Sociología del Trabajo en la Universidad de Buenos Aires. Mail: lucilafdurso@gmail.com

*** Argentina, Co-autora, Doctora en Ciencias Sociales (UBA). Docente de grado de la UNLP. Mail: longojulieta@gmail.com
} 


\section{Introducción}

En julio del 2014, cuando la autopartista Lear ${ }^{1}$ despidió a más de 200 trabajadores, se inició uno de los conflictos más importantes y extensos de los últimos años en Argentina. Más de seis meses de cortes de calle y movilizaciones -a las que le siguieron represiones, detenciones, fallos a favor y en contra por parte de la justicia, reincorporaciones, asambleas de destitución de delegados-, marcaron el desarrollo de un conflicto en la industria automotriz, un sector industrial estratégico para la economía nacional, que trascendió los muros de la fábrica y cobró visibilidad en la escena pública².

Generalmente, la temática de la conflictividad laboral en los espacios de trabajo ha sido abordada desde el campo disciplinar de la sociología del trabajo a partir de la relación, siempre dinámica y contradictoria, entre control y resistencia. Su estudio se planteó frecuentemente asociado a las estrategias de control y disciplinamiento patronal, y a las posibilidades que encontraban los trabajadores y sus organizaciones sindicales de expresar sus intereses de manera colectiva y modificar las relaciones de fuerza a su favor. Autores clásicos como Harry Breverman, Richard Edwards y Michael Burawoy profundizaron estas discusiones, centrando la atención en distintos aspectos de dicha relación ${ }^{3}$.

En este trabajo también nos enfocamos en el lugar de trabajo y abordamos una experiencia de sindicalismo de base ${ }^{4}$ fuertemente atravesada por la dinámica de la conflictividad laboral. No obstante, el eje de nuestra pregunta busca profundizar en la compleja relación entre sindicalismo y política. Concretamente, nos interesa indagar sobre los procesos de organización sindical de los trabajadores en el lugar de trabajo, la relación entre las experiencias de conflicto y la politización del espacio laboral, y las relaciones y/o tensiones que se abren entre el trabajo en las fábricas y la militancia de izquierda. El objetivo es comprender de qué modo se expresa la política en la cotidianeidad de la fábrica, cómo se articula el trabajo, la política y la acción sindical, y en qué medida la militancia de izquierda se plantea como un elemento externo (o no) al espacio de trabajo, considerando el caso de la autopartista Lear.

\footnotetext{
${ }^{1}$ Lear es una empresa multinacional norteamericana que cuenta con tres plantas en Argentina. El conflicto se desarrolló en la planta ubicada en la localidad de General Pacheco, en el norte del Gran Buenos Aires, que se dedica a la fabricación de mazos de cables para las empresas automotrices, principalmente para Ford.

2 Para un análisis en profundidad sobre el conflicto que tuvo lugar en la fábrica en 2014, ver Lucila D’Urso y Julieta Longo, "Radical Political Unionism as a Strategy for Revitalization in Argentina", Latin American Perspectives, 2017.

3 Para analizar distintos aspectos de este debate puede consultarse el artículo de Vicky Smith, "El legado de Braverman. La tradición del proceso de trabajo veinte años más tarde”, Revista Sociología del Trabajo, Nueva Época, 26, España,

1995. Para el caso argentino pueden mencionarse los trabajos de Claudia Figari: "La pericia técnica como campo en disputa: estrategias de control empresarial en filiales de empresas transnacionales radicadas en Argentina", Revista Sociedad y Economía, 30, 2016; y Agustín Santella, Labor conflict and capitalist hegemony in Argentina. The case of the automobile industry, 1990-2007, Leiden-Boston: Brill, 2016.

${ }_{4}^{4}$ Bajo esta expresión se agrupa, desde los primeros años del kirchnerismo en Argentina, a las experiencias de comisiones internas y cuerpos de delegados que se organizan en los lugares de trabajo y se definen en oposición a las direcciones sindicales burocráticas, reivindican la acción directa y las asambleas, y cuentan con la influencia de corrientes políticas de izquierda. Ver, María Celia Cotarelo, "Movimiento sindical en argentina 2004-2007: ¿anarquía sindical?”, XI Jornadas Interescuelas - San Miguel de Tucumán, Departamento de historia, Universidad Nacional de Tucumán, 2007; y Paula Varela, La disputa por la dignidad obrera. Sindicalismo de base fabril en la zona norte del Conurbano bonaerense 2003-2014, Buenos Aires, Imago Mundi-Colección Archivos, 2015.
} 
Dicho objetivo se inscribe en una serie de debates que vienen desarrollándose, no sólo en Argentina, sino también en el mundo anglosajón, en torno a la revitalización sindical 5 . Si bien es posible distinguir distintas perspectivas analíticas sobre la temática, todas comparten un mismo punto de partida: la revisión crítica de las teorías del "fin del trabajo" y de la "crisis o declive- del movimiento obrero". Así, frente a las teorías que cuestionaban el poder de las organizaciones sindicales para representar a una clase obrera cada vez más heterogénea y fragmentada, cobraron relevancia las interpretaciones que comenzaron a preguntarse por las estrategias que llevaban adelante para fortalecerse en un contexto de crisis, signado por el neoliberalismo y la globalización.

Como parte de estas discusiones y bajo el nombre de "sindicalismo político radical" (como traducción de radical political unionism), en los últimos años se desarrollaron una serie de debates que pusieron en el centro la dimensión política, en tanto elemento analítico ineludible para abordar las estrategias de revitalización sindical, introduciendo abiertamente la pregunta por las ideologías, las tradiciones políticas, y las orientaciones estratégicas que intervienen en las organizaciones sindicales, sobre todo en aquellas que se configuran en los lugares de trabajo ${ }^{6}$. A partir del abordaje de un caso de estudio, nuestra propuesta busca ser un aporte en el marco de estas discusiones, que vuelven a otorgar protagonismo a la compleja relación entre sindicalismo y política, y centran su mirada en el lugar de trabajo en tanto locus de organización y lucha de los trabajadores.

El artículo se divide en tres apartados. En primer lugar, planteamos una breve sección de notas metodológicas, donde detallamos las fuentes de información que utilizamos y argumentamos la decisión de recuperar una tradición sociológica clásica, anclada en el análisis de testimonios, en este caso, obreros. En segundo lugar, discutimos conceptualmente las particularidades que asume la división entre sindicalismo y política en el capitalismo, y su impacto sobre los procesos de organización y conflictividad en los lugares de trabajo. Y, en tercer lugar, visibilizamos las continuidades que pueden encontrarse entre sindicalismo y política en el caso de estudio, a partir de una serie de dimensiones analíticas que retomamos del desarrollo conceptual previo. A lo largo del artículo, argumentamos que centrar el análisis en los testimonios de los trabajadores nos permite cuestionar la escisión entre sindicalismo y

\footnotetext{
5 Entre algunos de los trabajos renombrados en el debate sobre revitalización sindical en el mundo anglosajón pueden mencionarse los de Carola Frege y John Kelly, "Union Revitalization Strategies in Comparative Perspective", European Journal of Industrial Relations, 9(1), 2003; Kim Moody "Towards an international social mouvement unionism", New Left Review, n. 225, 1988; Heather Connolly y Ralph Darlington, Radical political unionism in France and Britain: A comparative study of SUD-Rail and the RMT, European Journal of Industrial Relations, 18(3), 2012; Martin Upchurch y Andy Mathers, Neoliberal Globalization and Trade Unionism: Toward Radical Political Unionism? Critical Sociology, 38(2), 265-280, 2011. Para el caso argentino se destacan los aportes de Ruth Collier y Sebastián Etchemendy, "Golpeados pero de pie: Resurgimiento sindical y neocorporativismo segmentado en Argentina (2003-2007)", Postdata, (13), Buenos Aires, 2008; Cecilia Senén González y Julieta Haidar, "Revitalización sindical en perspectiva comparada. Un aporte al análisis sectorial en Argentina", en Arturo Fernández y Cecilia Senén González, Cecilia (comps), Estado, instituciones laborales y acción sindical en países del MERCOSUR frente al contexto de la crisis mundial, Buenos Aires, Prometeo, 2009; y Paula Varela, “¿Revitalización sindical sin debate de estrategias?”, en Paula Varela (Coord.) El gigante fragmentado. Trabajadores, sindicatos y política durante el kirchnerismo, Buenos Aires, Final abierto, 2016.

6 Entre algunos de los intelectuales que intervinieron en estos debates podemos mencionar a Ralph Darlington, Martin Upchurch y John McIlroy. Estas discusiones fueron publicadas en revistas especializadas en la temática, como Capital \& Class, European Journal of Industrial Relations, New Left Reviw y Critical Sociology, así como en distintos libros y compilaciones de artículos.
} 
política en el análisis de los procesos de organización y de conflictividad en las fábricas, pero también tomar distancia de aquellas definiciones que indican que "todo es política".

\section{Cómo aproximarnos a la relación entre lo sindical, lo político y la militancia de izquierda en los espacios de trabajo}

A mediados de los años '80 Michel Pialoux publicó en la revista francesa Actes de la recherche en sciences sociales una serie de notas donde transcribió "secuencias" de las numerosas conversaciones que tuvo con Christian Corouge, obrero de la fábrica Peugeot, dirigente sindical de la Confederation General du Travail francesa y militante del Partido Comunista Francés. El proyecto de ambos era construir un texto en el cual se transmitieran al mismo tiempo las condiciones de trabajo en la fábrica y los problemas de la acción militante. Según Pialoux, para comprender la atmósfera del taller y sus tiempos, para transmitir cómo se vive el trabajo y cómo es la relación entre los obreros y la política, era necesario dejar las reglas clásicas de la escritura académica y respetar la palabra de Corouge. Lo interesante de su propuesta es que deja de buscar respuestas simples en los relatos de los actores, muchas veces violentando -y recortando- los discursos para encontrar explicaciones. Para Pialoux era necesario dar cuenta de los deslizamientos entre un tema y otro, respetar los temas nuevos que aparecen en los relatos y tener en cuenta los recuerdos y emociones de los trabajadores que expresan lo más original y lo más específico, tanto de los discursos como de los entrevistados. Así, Pialoux demuestra que la política en las fábricas es indisociable de las condiciones en las que se trabaja, y también en las que se vive:

La manera en que se construye la relación con el sindicato y la política aparece estrechamente relacionada con las formas y condiciones singulares en las que se lleva a cabo el trabajo. Nos damos cuenta así de la importancia que tiene para una reflexión sobre la relación entre la lucha sindical y la lucha política, un análisis preciso de las condiciones sociales de constitución de una relación con la existencia, relación que se genera tanto en la vida fuera del trabajo como en la vida en el trabajo ${ }^{7}$.

Las reflexiones de estas notas sobre la vida en la fábrica se inscriben en una tradición en la cual se encuentra, por ejemplo, el clásico libro dirigido por Pierre Bourdieu La miseria del mundo 8 , La France Invisible 9 , y otros textos de Pialoux como Resister a la chaine ${ }^{10}, \mathrm{y}$ Repensar la condición obrera ${ }^{11}$. La traducción al castellano de este último libro inspiró nuestra decisión de recuperar esta tradición dentro de la sociología (muy fuertemente anclada en los testimonios, y particularmente interesada en la relación entre condiciones de trabajo y acción

\footnotetext{
7 Michel Pialoux, “Chronique Peugeot”, Actes de la Recherche en Sciences Social, vol. 52/53, N 1, 1984, p. 90.

8 Pierre Bourdieu, La miseria del mundo, Buenos Aires, Fondo de Cultura Económica, [1993] 1999.

${ }_{9}$ Stéphane Beaud, Joseph Confavreux y Jade Lindaard, La France Invisible, Paris, Éditions La Découverte/Poche, 2008.

10 Michel Pialoux y Christian Corouge, Résister à la chaine. Dialogue entre un ouvrier de Peugeot et un sociologue, Agone, 2011.

11 Stéphane Beaud y Michel Pialoux, Repensar la condición obrera. Investigación en las fábricas de Peugeot de Sochaux-Montbéliard. Buenos Aires, Antropofagia, 2015.
} 
militante) para discutir una temática sobre la que veníamos reflexionando tiempo antes: la relación entre sindicalismo y política. Cuando Beaud y Pialoux se preguntaban por qué adoptar esta postura metodológica, respondían:

Porque nos parecía que en el momento preciso en que realizábamos nuestra investigación, había un gran desajuste entre, por un lado, lo que observábamos en el terreno (...) y, por otro, la representación dominante que se daba de la realidad obrera (...). También era sumamente llamativo el desajuste entre lo que decían entonces los portavoces del mundo obrero (sindicalistas de alto nivel, permanentes, etc.) y lo que vivía la "base", lo que le costaba decir, y sobre todo su dificultad cada vez más grande para ser escuchada, incluso por aquellos que tenían como característica haber sido sus defensores naturales ("históricos") ${ }^{12}$

En cierto modo, estos desajustes también cobraban materialidad en nuestras preguntas de investigación en el caso particular de Lear. En las descripciones sobre las condiciones de trabajo y la organización sindical, pero sobre todo a partir del desarrollo del conflicto, fuimos identificando distintos modos en que se expresaba la relación entre lo sindical y lo político en el lugar de trabajo, que resultaba interesante problematizar y discutir.

La selección del caso de estudio responde a los siguientes motivos: a) la visibilidad y relevancia pública que tuvo el conflicto que protagonizaron los trabajadores de Lear en 2014; b) el proceso de organización sindical de base que venía configurándose en los últimos años en la planta, que derivó en 2011 en la elección de la única Comisión Interna (CI) opositora al Sindicato de Mecánicos y Afines del Transporte Automotor (SMATA), donde tenía influencia la izquierda; c) la importancia que tiene el sector automotriz en la economía del país y el crecimiento experimentado al menos hasta el año 201413; y d) a nuestra experiencia de investigación en el sector. Concretamente, Lucila D'Urso realizó en el marco de su tesis doctoral un extenso trabajo de campo en el sector automotriz de Argentina y Brasil14. Por su parte, Julieta Longo y Mariela Cambiasso formaron parte de un proyecto de investigación colectiva, en el cual se entrevistaron a delegados y activistas sindicales de terminales

\footnotetext{
12 Beaud, op. cit., pp. 388-389.

13 El sector automotriz transitó un significativo crecimiento durante el período 2003-2015. De acuerdo a datos proporcionados por la Encuesta Industrial Mensual (INDEC), entre 2002 (año de mayor depresión de la economía post crisis de 2001) y 2014 (último dato disponible), el Índice de Volumen Físico de Producción (IVF) del sector “Fabricación de vehículos automotores, remolques y semirremolques" creció a una tasa del 9.3\%, porcentaje superior al Nivel General de la Industria Manufacturera, donde la tasa de crecimiento anual promedio fue del 7.9\%. Asimismo, el empleo sectorial aumentó significativamente. El Índice de Obreros Ocupados (IOO) del sector automotriz creció un 6\%, es decir, en una proporción superior al nivel general de la industria (2.8\%).

14 En el marco de dicha investigación se realizaron veinticinco entrevistas a dirigentes y delegados sindicales, trabajadores de mandos medios y funcionarios públicos de la cartera laboral. Para el caso de Argentina, las entrevistas se realizaron entre los años 2013 y 2015 en el marco de proyectos de investigación dirigidos por Cecilia Senén González, financiados por el CONICET y la UBA. También fueron analizados los convenios y acuerdos colectivos que rigieron la actividad automotriz en Brasil y Argentina entre los años 2003 y 2014, distintas fuentes periodísticas, bases estadísticas y documentos empresariales. Esta información se complementó con visitas a la planta industrial de Ford ubicada en General Pacheco.
} 
automotrices y plantas autopartistas de la Zona Norte del Conurbano Bonaerense, y a dirigentes del SMATA ${ }^{15}$.

Si bien tendremos en consideración la totalidad de los datos primarios y secundarios relevados, en este artículo nos focalizaremos en el análisis de una serie de entrevistas en profundidad con Hernán y Daniel, dos dirigentes de la fábrica autopartista Lear quienes, como consecuencia del proceso de organización en el espacio de trabajo, iniciaron su militancia en un partido político de izquierda ${ }^{16}$. Esta decisión se desprende del objetivo que nos planteamos en el artículo que, como mencionamos previamente, pretende discutir la relación entre sindicalismo, política y militancia de izquierda en la actualidad, prestando atención a las organizaciones de trabajadores que se configuran en los espacios de trabajo.

Al momento de hacer las entrevistas, Hernán tenía 35 años. Había sido delegado de la planta y se definía como parte de la "generación del 2001", año donde se desató la última crisis social, económica y política de Argentina. Ese año estaba trabajando como contratado en Lear y fue despedido junto con ochenta de sus compañeros. Sus experiencias políticas comienzan antes del ingreso en la fábrica y se trazan familiarmente. Es hijo de uno de los delegados que organizó la fábrica Corni ${ }^{17}$ durante la dictadura militar, vivió en su casa la desocupación de los '90 y estuvo en "la plaza en 2001"18. Antes de ingresar como efectivo a Lear, trabajó en la construcción, en fábricas químicas y del plástico. Si bien había intentado mejorar sus condiciones de trabajo, nunca se había organizado ni había militado en un partido político.

Daniel tenía 27 años. Había sido activista durante el conflicto y se definía como parte de la "generación del nunca menos", en referencia a la generación que comenzó a trabajar en el marco del crecimiento económico y del empleo de 2003 en adelante. En Lear construyó sus primeras experiencias laborales, sindicales y también políticas. En el marco de las entrevistas reflexionó sobre sus acercamientos iniciales a la militancia política, cuando acompañaba a su tío a los plenarios y movilizaciones del Movimiento Teresa Rodríguez (MTR) ${ }^{19}$.

En 2005, el mismo año en que Hernán y Daniel entraron a trabajar a Lear, comenzaba a gestarse en la planta una organización opositora al SMATA por iniciativa de dos militantes del Partido de los Trabajadores Socialistas (PTS), que ingresaron a la fábrica con ese objetivo. Con una composición heterogénea -en la que intervenían trabajadores independientes y

\footnotetext{
15 Entre los años 2013 y 2015 se realizaron entrevistas a dos dirigentes nacionales del SMATA, y nueve entrevistas a delegados y activistas de las plantas Ford, Volkswagen, Toyota, Lear, Kromberg y Gestamp. Asimismo, se analizaron los boletines y volantes que realizaron los trabajadores durante los conflictos y se realizaron observaciones de campo en encuentros sindicales donde participaban los trabajadores que pertenecían a comisiones internas combativas (los cuales se denominaron Encuentros de Trabajadores Combativos de Zona Norte). Este trabajo de campo se realizó en el marco de un proyecto de investigación más amplio, financiado por UBACyT y dirigido por Paula Varela, en el que se entrevistaron a delegados y activistas de 19 plantas industriales de la Zona Norte del Conurbano Bonaerense. Ver: Paula Varela, El gigante fragmentado. Sindicatos, trabajadores y política durante el kirchnerismo, Buenos Aires, Editorial Final Abierto, 2016.

${ }^{16}$ Hernán y Daniel son militantes del Partido de los Trabajadores Socialistas (PTS), un partido político trotskista de Argentina. Sus nombres han sido modificados para resguardar su anonimato.

17 Fábrica de fundición ubicada en la zona norte del Gran Buenos Aires. Durante los años setenta fue parte de la oposición a la dirección del gremio en la seccional Vicente López, dirigida por Gregorio Minguito.

18 Se refiere a las manifestaciones que sucedieron el 19 y 20 de diciembre de 2001, que terminaron con el derrocamiento del gobierno de la Alianza de Fernando De la Rúa.

19 MTR es un movimiento de trabajadores desocupados que surge en 1998 tras la ruptura del MTD Teresa Rodríguez.
} 
militantes de izquierda- esta organización desplazó paulatinamente a la Lista Verde oficialista, que había dirigido la CI de la planta hasta ese momento. Los trabajadores se organizaron primero clandestinamente y fuera de la fábrica, en partidos de fútbol y reuniones sociales. En el año 2007 un delegado independiente fue elegido en las elecciones internas, en 2009 conquistaron tres delegados y en 2011 desplazaron a todos los delegados oficialistas, apelando a una consigna muy amplia: "que todo se decida en asamblea"20. Durante este proceso, Hernán y Daniel participaron en la organización sindical opositora e iniciaron su militancia partidaria.

Realizamos las entrevistas en el 2015, un año después del conflicto, con el objetivo de reconstruir el proceso de lucha y organización en la fábrica. En ese momento la situación en la planta era otra: después de varios de meses de lucha la gran mayoría de los más de 200 trabajadores despedidos había aceptado la indemnización, al igual que casi todos los delegados de la CI. Hernán era el único delegado de la Lista Celeste que aún se encontraba trabajando en la planta. Daniel había sido reincorporado algunas semanas antes, luego de un fallo de la justicia laboral, y había sido agredido dentro de la fábrica por activistas oficialistas del SMATA. La amplitud del temario, así como la reiteración de los encuentros nos permitió conocer sus experiencias y opiniones sobre el desarrollo del extenso conflicto de 2014, pero también sobre distintas temáticas que hacían a sus condiciones sociales y personales, como sus trayectorias familiares y políticas, sus experiencias en la fábrica, sus visiones acerca del conflicto y sobre la militancia. Estas charlas abrieron la posibilidad de reflexionar acerca de los límites difusos de la política en los lugares de trabajo, sobre las singularidades de la política de izquierda y sobre las relaciones entre militancia sindical y militancia partidaria. Buscamos recuperar estos temas, difíciles de abordar y muchas veces relegados en los estudios académicos, a partir del relato de los entrevistados, respetando el modo en que ellos describen y nos cuentan su experiencia. En este sentido, el análisis en profundidad de las entrevistas que mantuvimos con Hernán y Daniel, busca ser un aporte para ampliar las discusiones sobre una pregunta que consideramos fundamental en los estudios sindicales actuales: ¿de qué modo se expresa lo político en las fábricas?

\section{La separación de lo económico y lo político}

El movimiento obrero argentino sufrió un fuerte proceso de expansión con el triunfo del peronismo en la década de 1940. El peronismo sentó las bases de los grandes sindicatos de masas por rama de actividad, configurando un modelo sindical fuertemente estatizado, institucionalizado y centralizado a nivel de las direcciones sindicales, combinado con un proceso de organización sindical de base en los lugares de trabajo que, si bien tenía una historia previa en el país, se expandió cuantitativa y cualitativamente a partir de entonces ${ }^{21}$.

\footnotetext{
20 Por estatuto, las elecciones internas en el SMATA son nominales. Sin embargo, dado que los delegados opositores comenzaban a conquistar posiciones en el espacio de trabajo, la dirección del gremio decidió organizar en 2011 una elección por lista de candidatos, con el objetivo de desplazar a todos los delegados opositores. En ese marco, la oposición conforma la Lista Celeste, gana la dirección de la CI en 2011 y renueva su mandato con el 70\% de los votos en 2013. Finalmente, la experiencia de la Lista Celeste fue desarticulada tras el conflicto por los despidos de 2014.

21 Paula Lenguita y Paula Varela, "Una reflexión sobre el rol de las comisiones internas en el sindicalismo argentino", Claudia Figari, Paula Lenguita y Juan Montes Cató (comp.) El movimiento obrero en disputa. La organización colectiva de los trabajadores, su lucha y resistencia en la Argentina del siglo XX, Buenos Aires, Ediciones
} 
Esta combinación inspiró en Adolfo Gilly22 la definición de "anomalía" para referirse al caso argentino. Enfocando la atención en las comisiones internas y cuerpo de delegados, sostuvo que la organización de los trabajadores en su lugar de trabajo no solo operaba en defensa de los intereses económicos inmediatos, sino que tendía a cuestionar (potencial y efectivamente) la dominación capitalista en su conjunto. Así, su modo de existencia y de funcionamiento, con la posibilidad de elegir delegados y debatir posiciones en asamblea, introducía la política en la fábrica, en tanto habilitaba el proceso de discusión colectiva y formación de opinión sobre la política del país y del Estado.

Esta potencialidad, así como el carácter militante de la acción sindical que se configura en el lugar de trabajo, fue destacada por diversos autores especializados y analizada en distintos estudios de caso en el campo de la historia, la sociología y la antropología. De este modo, la relación entre lo sindical y lo político ha atravesado las discusiones sobre sindicalismo en Argentina y, más o menos explícitamente, tiene una presencia relevante en los debates académicos sobre la temática.

De hecho, en las interpretaciones más difundidas sobre la dinámica sindical en la actualidad, lo político ha sido un elemento de análisis ineludible para explicar el proceso de nuevo protagonismo de las organizaciones sindicales que diversos autores identificaron de 2003 en adelante ${ }^{23}$. Sin embargo, estas miradas generalmente se han concentrado en el estudio de las dirigencias sindicales y en su relación con el Estado.

También, en los últimos años, estas discusiones aparecieron más explícitamente referidas en los análisis sobre el denominado sindicalismo de base. De la mano del resurgir de la acción sindical, algunos estudios enfocaron su mirada en la organización gremial en el espacio de trabajo, a partir del análisis de distintos casos de estudio ${ }^{24}$. Desde un enfoque crítico a las lecturas institucionalistas, estos estudios indagaron principalmente acerca de la existencia de prácticas más democráticas en los lugares de trabajo y su posibilidad de renovar

Ciccus, 2010. Para un análisis historiográfico sobre las organizaciones sindicales en los lugares de trabajo durante los años previos al triunfo del peronismo y su relación con distintas corrientes políticas de izquierda pueden consultarse los trabajos de Hernán Camarero, A la conquista de la clase obrera. Los comunistas y el mundo del trabajo en la Argentina, 1920-1935. Buenos Aires, Siglo XXI, 2007; y Diego Ceruso, La izquierda en la fábrica. La militancia obrera industrial en el lugar de trabajo, 1916-1943, Buenos Aires, Imago Mundi, 2015.

22 Adolfo Gilly, "La anomalía argentina (Estado, Corporaciones y trabajadores)", El estado en América Latina: teoría y práctica, México, DF, Siglo XXI, 1990.

23 Etchemendy, op. cit., 2008; Senén González, op. cit., 2009.

24 Las tesis de doctorado que abordan esta problemática en los últimos años nos permiten comprender la magnitud de ese proceso y el interés que revistió para los estudios académicos: Paula Lenguita, La política del teletrabajo. Un estudio comparativo sobre las ideologías y prácticas de control laboral destinadas a los teletrabajadores a domicilio en la Argentina, Tesis de Doctorado en Ciencias Sociales, UBA, 2006; Juan Montes Cató, Dominación y resistencia en los espacios de trabajo. Estudio sobre las relaciones de trabajo en empresas de telecomunicaciones, Tesis de Doctorado en Ciencias Sociales, UBA, 2006; Santiago Duhalde, La vida al interior del sindicato. Estudio de caso sobre la dinámica interna de la asociación trabajadores del estado, 2003-2008, Tesis de doctorado en co-tutela. Universidad de Buenos Aires - Universidad de Paris VIII - Vincennes-Saint-Denis, 2011; Patricia Ventrici, Sindicalismo de base en la Argentina contemporánea. El cuerpo de delegados del subterráneo, Tesis de Doctorado en Ciencias Sociales, UBA, 2011; Julieta Longo, ¿Renovación de las tradiciones sindicales en ámbitos laborales precarizados? Un análisis de las organizaciones sindicales en empresas supermercadistas durante la posconvertibilidad, Tesis de Doctorado en Ciencias Sociales, UBA, 2014; Mariela Cambiasso, Tradición de organización y estrategias sindicales. Un estudio sobre la organización sindical en la fábrica alimenticia KraftMondelez (ex Terrabusi) en la post-convertibilidad, Tesis de Doctorado en Ciencias Sociales, UBA, 2015; Varela, 2015, op. cit. 
al sindicalismo burocratizado de los años '90. Más recientemente también comenzaron a discutirse las estrategias y las orientaciones políticas de las organizaciones sindicales de base $^{25}$. Este artículo se inscribe en esta segunda línea de estudios.

Asimismo, retomamos parte de las discusiones que se desarrollaron en el marco de los debates anglosajones sobre revitalización sindical, entre cuyos referentes nos interesa destacar a Sheila Cohen ${ }^{26}$, por sus aportes para problematizar la compleja relación entre los sindicatos, la política, y la militancia de izquierda (left agency), a partir de experiencias concretas de organización gremial de base. Cohen se pregunta por el modo en que se politizan las acciones de los trabajadores en el espacio laboral, considerando las condiciones estructurales de explotación del trabajo y la influencia de corrientes políticas de izquierda a través de los delegados de base. Para ello, la autora parte un análisis crítico sobre la militancia que llevaron adelante los activistas de la izquierda revolucionaria durante las décadas de 1970 y 1980 en el marco del avance del neoliberalismo, por plantear una agenda con consignas extra-laborales, desarticuladas de las demandas específicas de los trabajadores. Según argumenta Cohen, esta situación, que debilitó la capacidad de resistencia de los trabajadores en un contexto de avance del capital sobre el trabajo, configura una paradoja inherente a la militancia de izquierda.

En función del objetivo que se propone el artículo, el planteo de la autora es interesante principalmente por dos motivos. Por un lado, porque se enfoca en el lugar de trabajo y en la actividad de los líderes y activistas de izquierda, en tanto agentes cruciales en la dinámica de la resistencia de la clase trabajadora ${ }^{27} \mathrm{y}$, por otro lado, porque reconoce la separación entre economía y política como un límite para la acción revolucionaria de los trabajadores. En este último punto se ubica su cuestionamiento a la política que se configura por fuera de las demandas económicas inmediatas de los trabajadores, y su defensa de la politización que implica la toma de conciencia a partir de las contradicciones experimentadas en el lugar de trabajo. Para Cohen el problema se plantea cuando no existe relación entre la política de izquierda y las problemáticas relacionadas con la explotación que surgen en el lugar de trabajo. Justamente, sostiene que lo que socaba la eficiencia de la militancia de izquierda es la falta de fusión entre los ideales revolucionarios y el contenido de clase de los problemas sindicales que se desarrollan en el espacio laboral.

Otra autora que también aborda estos problemas es Ellen Meiksins Wood. Pero, mientas Cohen marca las contradicciones entre economía y política y sus efectos para la organización y resistencia de los trabajadores, Meiksins Wood desarrolla su análisis a partir de las contradicciones propias del capitalismo. En su texto clásico "La separación de lo "económico" y lo "político" en el capitalismo" 28, sostiene que, a diferencia de otros modos de

\footnotetext{
25 Varela, 2015, op. cit.; D’Urso y Longo, 2017, op. cit.; Cambiasso, 2015, op. cit. y Clara Marticorena, “¿Sindicalismo de base vs. sindicalismo en la base? Un aporte al debate sobre revitalización sindical en Argentina a partir del análisis de la organización y dinámica sindical en el sector químico", VIII Congreso Latinoamericano de Estudios del Trabajo (ALAST), Buenos Aires, 2016.

26 Sheila Cohen, "Left agency and class action: The paradox of workplace radicalism", Capital \& Class, vol. 35, nํㅜ, 2011.

27 Otro autor que se ha enfocado en la importancia de los líderes sindicales en la movilización de los trabajadores es John Kelly, ver John Kelly, Rethinking industrial relations. Mobilization, collectivism and long waves, London, Routledge, 1988.

28 Ellen Meiksins Wood, "La separación de lo "económico" y lo "político" en el capitalismo", Ellen Meiksins Wood, Democracia contra capitalismo. México DF, Siglo XXI, 2000.
} 
producción, el capitalismo se caracteriza por la diferenciación entre las esferas económica y política. Esta posibilidad deriva de la doble libertad de la fuerza de trabajo, que hace innecesaria la presión extraeconómica en el momento de la producción: es la propia necesidad económica la que obliga al trabajador a vender su fuerza de trabajo.

Ahora bien, esta separación no implica que la política esté ausente en las relaciones de producción, sino que adquiere una naturaleza singular. El capitalismo, señala la autora, es único porque si bien lo político está en la organización misma de la producción y garantiza un grado de control sin precedentes del capital sobre el trabajo, las relaciones de producción son visibilizadas como relaciones económicas y no políticas. Esta diferenciación tiene efectos prácticos que se expresan, por ejemplo, en la separación entre las luchas políticas y las luchas económicas.

Recuperando este análisis podemos diferenciar algunos elementos para pensar la política en el lugar de trabajo. Las relaciones que se establecen en las fábricas son relaciones de poder, en tanto implican la compra-venta de fuerza de trabajo y la apropiación del plustrabajo. Pero consideraremos que estas relaciones se politizan cuando son visibilizadas como relaciones de explotación (de clase) y no puramente como relaciones económicas de producción. De este modo, cuando hablamos de politización en el espacio de trabajo nos referimos a dos procesos específicos: (a) la posibilidad de que las relaciones sociales de producción sean entendidas como relaciones de explotación, y (b) la posibilidad de conectar ámbitos que aparecen en principio separados: lo público y lo privado o, en el caso que analizamos, lo que sucede afuera y adentro de la fábrica.

En términos generales, no interpretamos que los procesos de politización estén necesariamente vinculados con un tipo de estrategia política, sino con la posibilidad de significar las relaciones sociales de producción como relaciones de explotación, es decir, como relaciones políticas.

Desde este punto de vista, la pregunta no es si el conflicto de Lear fue un conflicto sindical o político, sino qué continuidades pueden rastrearse entre economía y política a lo largo del proceso de lucha. Por ello, sostenemos que para analizar los procesos de politización es necesario comenzar a mirar concretamente las experiencias de lucha y de organización que llevan adelante las y los trabajadores en sus lugares de trabajo.

En este análisis retomaremos tres dimensiones que están presentes en el planteo de Meiksins Wood y que nos ayudan a interpretar los relatos de los entrevistados: (a) la transformación de las luchas por la apropiación en disputas aparentemente no políticas, (b) la localización de la lucha de clases en el punto de la producción, y (c) la vinculación entre conciencia política y militancia a nivel intrafabril. A partir de estas tres dimensiones organizamos la discusión en el siguiente apartado.

\section{Lo sindical y lo político en Lear}

\subsection{La politización de "lo sindical”}

Pese a que las formas de explotación implican relaciones de poder, lo distintivo del capitalismo es que la apropiación de la fuerza de trabajo excedente tiene lugar en la esfera 
económica, con medios económicos. Así, el modo de producción capitalista no desvincula la explotación del poder, pero separa, temporal y espacialmente, el momento de coerción del momento de apropiación. Tal como señala Meiskins Wood, la separación entre las luchas económicas y las luchas políticas reproduce la dicotomía entre el Estado -terreno de los intereses generales y de la política- y la sociedad civil -donde el interés privado económico actuaría independientemente de lo político y donde las luchas serían económicas-. La diferenciación de ambas esferas como ámbitos independientes invisibiliza el contenido político de las luchas que se desarrollan en la sociedad civil, en el terreno privado y principalmente en los espacios de producción. Así, las luchas de poder que suceden a este nivel, se significan como luchas económicas.

Estas reflexiones se vuelven interesantes para analizar el discurso de Hernán y Daniel. Si bien, como señala Meiksins Wood, la coerción se ejerce temporalmente antes que la apropiación del plustrabajo en las fábricas, la violencia también aparece cotidianamente en los espacios de trabajo. Sus relatos sobre las condiciones de trabajo nos permiten comprender cómo se experimenta cotidianamente esta violencia:

Hernán: Bueno, yo estuve 3 años en el turno tarde. Y estuvimos 9 meses trabajando 13 horas por día. De lunes a lunes más o menos. Entrábamos a las 11 de la mañana y salíamos casi a las 12 de la noche. Bueno y ahí [además] había otros problemas como los del comedor, los problemas de contratados...

Daniel: La ropa...

Hernán: Que no te entregan la ropa. Bueno es como que [cuando estás contratado por agencia de empleo eventual] sos de segunda ¿viste? Encima te daban la comida... que se yo, venía una milanesa, pero la milanesa por dentro era negra. ¡No te digo que a la mañana se comía bien, pero se comía mejor! A la tarde te dejaban lo que sobraba. Entrevista a Hernán y Daniel. Realizada el 3 de julio de 2015.

Hernán: [En el 2005] empezaron a cambiar los procesos, empezaron a agregar cosas, a sacar cosas [se refiere a las tareas que tienen que realizar en el proceso de trabajo]. Te iban sacando cosas, pero iban aumentando los ritmos. Dejaron de existir los tableros fijos y empezaron a trabajar sobre los continuos, sobre los "rotary".

Daniel: Sí, pasó de ser un trabajo más tranquilo a ser algo repetitivo, ya como más despiadado, en el sentido de los ritmos.

Hernán: Antes, ponele, entrabas a trabajar y eran las 12 del mediodía y ya terminabas tu producción, y te quedaban 3 horas. Ahora no, es de 6 de la mañana a 3 de la tarde y todo el tiempo laburando. ¡Y no a un ritmo bajo! Sino que son cada vez más altos los ritmos. Llegás al viernes hecho mierda, a veces si llegás... Entrevista a Hernán y Daniel. Realizada el 3 de julio de 2015.

La violencia que implica "ser trabajador de segunda" o trabajar a los ritmos que impone la empresa, no se vivencia necesariamente como el resultado de una disputa política: los reclamos que surgen en la esfera de la fábrica son leídos, en un primer nivel, como conflictos sindicales. Esta violencia es la que explica, en los relatos de los entrevistados, la conformación de una organización sindical opositora a la dirección del sindicato, pero que no pone en riesgo necesaria e inmediatamente la separación entre lo sindical y lo político en el terreno de la producción. 
En el relato del día a día en la fábrica, lo político surge vinculado con lo que ocurre fuera de las fronteras del espacio de trabajo. En la primera entrevista, buscando diferenciar el conflicto de 2014 de un conflicto previo que tuvo lugar en la fábrica en 201329, Daniel señalaba que el conflicto por los despidos fue distinto porque fue "político":

Daniel: ... Y sindical en 2013, en el sentido de que si bien tenía ribetes políticos -por lo que fue la caída del sumario, la denuncia de los derechos humanos, la denuncia al INADI ${ }^{30}$, la Comisión de Mujeres-, pero fue sindical porque era en base a los reclamos más sentidos de la fábrica. En el 2014 fue sobre los despidos y las suspensiones, y fue tomando ese carácter [político] por la dinámica del conflicto. Los tipos dejaron a la CI afuera y se terminó peleando en las calles. Y empezó el enfrentamiento con el gobierno, con la gendarmería y con el poder real del Estado. Entrevista a Daniel. Realizada el 15 de julio de 2015 .

De esta manera, si bien teóricamente podemos afirmar que el momento de la explotación implica necesariamente luchas de poder y relaciones políticas, es interesante observar cómo estos elementos aparecían escindidos en las experiencias de los trabajadores. Recién cuando el conflicto deja la fábrica y se desplaza a las calles, para los entrevistados se vuelve explícito el carácter político de la explotación. Desde luego, este momento adquiere una significación particular. El enfrentamiento no es únicamente con la empresa, sino también con el Estado. Asimismo, la participación de una multiplicidad de organizaciones -sociales, estudiantiles, sindicales- puso en evidencia de un modo más inmediato el carácter político de la lucha. En palabras de Meiksins Wood:

El conflicto de clases por lo general se convierte en una guerra declarada sólo cuando se exterioriza, en particular porque el brazo coercitivo del capital está fuera de los límites de la unidad productiva. Esto significa que cuando surgen confrontaciones violentas por lo general no son directamente entre el capital y la mano de obra. No es el capital en sí, sino el estado, el que se hace cargo del conflicto de clases cuando intermitentemente rebasa los muros y adopta una forma más violenta ${ }^{31}$.

En estos términos, es posible afirmar que la politización de las relaciones de producción se desarrolla de manera acelerada cuando la disputa de intereses en el lugar de trabajo abandona el espacio privado de la fábrica, y se despliega en el espacio público, en "la calle".

\footnotetext{
${ }^{29}$ En 2013 los trabajadores consiguen que la empresa vuelva a pagar un bono anual de 100 horas. Durante ese conflicto la empresa despidió 16 trabajadores, que luego fueron reincorporados.

30 INADI: Instituto Nacional contra la Discriminación, Xenofobia y el Racismo

31 Meiksins Wood, op. cit., pp. 55.
} 


\subsection{Las particularidades de "lo político" en el espacio de trabajo}

Hasta aquí hemos explicado el modo en que en el capitalismo se produce una separación de las esferas política y económica, que hace que las relaciones de explotación no sean visibilizadas en el lugar de trabajo como relaciones políticas, sino económicas.

Ahora bien, como vimos, la dimensión política no aparece recién cuando el conflicto desborda las fronteras del espacio de producción. Esto nos reenvía nuevamente a la fábrica, donde en términos de Adolfo Gilly:

... se asegura la extracción del producto excedente y la reproducción del sistema, allí donde se contraponen el despotismo industrial y la cooperación en un enfrentamiento de todos los instantes como potencias complementarias y antagónicas de la sociedad capitalista, [aquel locus de contradicciones y disputas en el cual] se introduce la política ${ }^{32}$.

Tal como mencionamos anteriormente, Gilly argumenta que las diversas instancias organizativas del lugar de trabajo intervienen no sólo en cuestiones de índole salarial, sino que también asumen funciones vinculadas con la disputa por el control del proceso de trabajo, y que a partir de estas disputas se introduce la dimensión política en las fábricas. También Meiksins Wood define a la fábrica como una: “... unidad altamente organizada e integrada con su propia jerarquía y estructura de autoridad que contiene en sí misma las principales causas del conflicto de clases"33. Pero además sostiene que: "la naturaleza de la clase trabajadora independiente es tal, que las nuevas formas de organización y resistencia de los obreros se han incorporado al proceso de producción"34. De este modo, vemos que el lugar de trabajo se presenta como locus de dominación, pero también de organización y resistencia. Estos elementos no escapan de la experiencia de los trabajadores de Lear.

La dimensión política de las demandas movilizadas por la CI (definidas en primera instancia como sindicales) se revela con mayor claridad cuando uno de los delegados de la fábrica explica el modo en que los ritmos de trabajo afectan e incluso definen los ritmos de vida de los trabajadores.

Daniel: ... en el día a día los obreros no lo ven. Entran de noche a trabajar a las seis de la mañana, salen a las seis de la tarde y ya es de noche otra vez. Llegan de trabajar y se acuestan a dormir y no disfrutan con los hijos, no disfrutan a la familia, dejan de lado un montón de cosas, su salud, un montón de cosas. A costa de -supuestamente- ciertas mejoras que nunca llegan. Y siempre van corriendo detrás de una ruedita que nunca para, porque vos conseguiste un aumento en una paritaria y se lo lleva el aumento de las cosas. Al otro día tenés que pagar más alquiler, más cosas. Entonces empezar a interpelar en las reflexiones de los laburantes hace que surjan procesos como la [Lista] Celeste. Entrevista a Daniel. Realizada el 15 de julio de 2015.

\footnotetext{
32 Gilly, op. cit., pp. 23.

33 Meiksins Wood, op. cit., pp. 55.

34 Ibid., pp. 51-52.
} 
La conformación de una CI opositora a la dirigencia sindical se produce sobre esta base. Es decir, sobre un descontento que aparecía signado por luchas salariales que se entremezclaba con la intensificación de la jornada y los ritmos de trabajo, cuyas consecuencias afectaban directamente la vida y la salud de los trabajadores, aunque no fueran necesariamente así percibidas por ellos. Al ponerse en discusión el tiempo y el modo de vida dentro y fuera de la fábrica, los reclamos se politizan, tal como puede observase en el siguiente fragmento:

Daniel: ...en el 2014 (...) arrancamos el tema de un boletín donde planteamos un informe sobre las enfermedades laborales. Hicimos una encuesta en toda la fábrica, ya algo más científico, de cuáles eran los dolores, cuáles eran los ritmos, cuáles eran los problemas. Y con todo eso sacamos un boletín. Nosotros ya veníamos sacando un boletín, pero cada tanto, y ahora nos proponíamos sacar un boletín mensual donde había una sección especial sobre enfermedades laborales (...) Y bueno, claro, lo que pasa es que era algo que nos llevaba a un enfrentamiento directo [con la empresa], porque desde ya que el flujo de la ganancia de la empresa va por ese sentido. Sacar el boletín era empezar a disputar de algún modo la ganancia de los tipos con el tema de las enfermedades y todo eso... Entrevista a Daniel. Realizada el 15 de julio de 2015.

En el relato, el aumento de la ganancia empresaria se contrapone a la salud de los obreros y la disposición de sus tiempos. Dicha contraposición, así planteada, comienza a significar a las condiciones de trabajo de un carácter político, en la medida en que visibiliza las relaciones de producción como relaciones de explotación, al tiempo que conecta el trabajo en la fábrica con las condiciones de vida fuera de la fábrica. No se trata solamente de poner en cuestión la distribución de las ganancias y los salarios, sino que se cuestiona el uso que hace la empresa de los obreros, la disposición de sus cuerpos en tanto mera fuerza de trabajo. A su vez, la posibilidad de manifestar "opiniones, planteos y reclamos", permite re-subjetivizar a la producción y también a los trabajadores. De este modo, la politización de las relaciones de producción no sólo operó a partir del conflicto por los despidos de 2014, sino que la dinámica del enfrentamiento fuera de las instalaciones de la fábrica también contribuyó a resignificar los procesos de lucha y de organización que lo antecedieron. Las demandas por condiciones de trabajo y de contratación, en contra de los altos ritmos de producción y las enfermedades laborales, contribuyeron a visibilizar que esos reclamos atacaban directamente el pleno ejercicio del poder de decisión de la empresa sobre la producción, es decir, ponían en cuestión su pleno control del proceso de trabajo.

\subsection{Lo político y lo partidario: la militancia de izquierda}

En este apartado nos interesa analizar cómo la politización que opera en el lugar de trabajo se articula con la militancia política. Meiksins Wood se opone a las miradas que resaltan el carácter "economicista" de la clase trabajadora como reflejo de una falta de conciencia política, considerando que:

...es importante reconocer que el llamado "economicismo" de las actitudes de la clase trabajadora no refleja tanto una falta de conciencia política como 
un cambio objetivo de la ubicación de la política, un cambio en la arena y los objetos de la lucha política inherente a la estructura misma de la producción capitalista ${ }^{35}$.

Pensar que el economicismo de las actitudes de los trabajadores es el resultado del desplazamiento de la política fuera del espacio de trabajo, y por lo tanto del triunfo de un tipo singular de estrategia política, nos permite también analizar el movimiento contrario. ¿Qué sucede cuando comienza a instalarse una estrategia que se propone reintroducir la política en el espacio de trabajo? Partir de esta pregunta es interesante para analizar los deslizamientos que encontramos en los relatos de Hernán y Daniel entre la lucha por demandas sindicales y la militancia política. En este sentido, cuando les preguntamos acerca de las principales demandas que impulsaban la organización, Hernán nos decía:

Los ritmos de trabajo, el salario no tanto. Si bien uno es consciente de que siempre está bueno pelear por salario, pero no es una demanda muy sentida. Es una demanda sentida, no le quiero sacar peso, pero lo que más motorizó para mí fue eso, la falta de democracia, los ritmos de producción y las condiciones cada vez peores en las cuales trabajamos. Hasta el 2008 el salario era más o menos bueno, después del 2008 empezó a decaer, entonces son diferentes momentos. Cuando yo me empecé a organizar, me acuerdo que Gastón ${ }^{36}$ hablaba mucho conmigo (...) Yo lo escuchaba, después empecé a entender un poco más (...) Entonces, ¿viste en el 2008 cuando estalla la crisis? [se refiere a la crisis financiera en Estados Unidos que impacta fuertemente en el sector automotriz], acá en Lear repercutió echando a los contratados. Yo recuerdo que estaba trabajando, y pasa el delegado [de la Lista Verde oficialista] y me dice "iQué hacés Potro!", porque saludaba a todo el mundo así. Le digo "che Rodrigo, ¿qué onda?, ¿van a echar gente?", "Sí van a echar a los contratados", "Pero, ¿no se puede hacer nada? Si los ritmos de producción siguen estando igual, aparte ¡es allá! ¡Nosotros qué tenemos que ver!", "Y no Potro... no pasa nada, vos seguí laburando" y se fue. Y yo dije "¡uh!", no me gustó nada (...) Y a los dos meses pasa otra vez, y le digo "Che Rodrigo, ¿otra vez van a echar gente?". Iban a echar 40 efectivos. "Si Potro, pero vos quedate tranquilo ¡si vos trabajás!", me dice, "acá van a echar a los que están en contra nuestra, los que no le sirven a la empresa, y los "rotos"37. Y ya cuando me dijo eso me crucé a otra línea [de producción] y empecé a hablar con los otros (...) Y ahí ya me empecé a juntar, me empecé a meter más seriamente. Entrevista a Hernán y Daniel. Realizada el 3 de julio de 2015.

En el relato de Hernán se plantea casi linealmente la articulación entre las arbitrariedades de la patronal, la ausencia de representación de las demandas por parte de los delegados oficialistas y la necesidad de los trabajadores de organizarse por fuera y en forma independiente de ambas estructuras. En este sentido, es interesante cómo la pregunta en

\footnotetext{
35 Ibid., pp. 56.

36 Gastón fue uno de los primeros activistas opositores de la fábrica. Modificamos su nombre, para garantizar su anonimato.

37 Con ese término se refieren a los trabajadores que tienen enfermedades laborales, la mayoría de las veces, crónicas.
} 
torno a las principales demandas en la fábrica, aquellas que son más sentidas por los trabajadores, deriva en las reflexiones sobre sus primeros pasos en la militancia sindical y partidaria que, como vimos, no pueden comprenderse por fuera de sus vivencias de explotación en la fábrica. Este deslizamiento entre temas, nos permite comprender cómo las vivencias ligadas a las condiciones de trabajo se vinculan con la militancia.

La pregunta es cómo y por qué comienzan a borrarse los límites que dividen sindicalismo y política, en definitiva, cómo se politizan las relaciones de producción.

Lo que vemos es que la militancia y la organización independiente de los trabajadores (de la empresa y de la dirección del sindicato) contribuyen a cuestionar aquella separación, y operan esfumando sus contornos. Demandas aparentemente sindicales, en el marco de una organización sindical opositora a la dirección del SMATA, vuelven a la militancia como posible y necesaria.

Asimismo, la organización en la fábrica y la militancia se plantean sobre la base de la configuración de otro tipo de relaciones sociales, donde la solidaridad entre los trabajadores se define como un eje central. En la experiencia de Hernán no es un reclamo individual el que termina de impulsar su decisión de acercarse a la organización que estaba conformándose en la fábrica, sino la oposición frente a la arbitrariedad de la empresa a la hora despedir trabajadores contratados, una situación que él mismo había vivido en Lear años atrás. La lucha contra la división entre efectivos y contratados formaba parte del programa de la organización opositora en la fábrica, y también de la experiencia laboral de Hernán. En este sentido, puede observarse el rol de la militancia de izquierda en la construcción de las demandas de los trabajadores que, al articularse con sus intereses inmediatos, coloca a la política en el centro de las relaciones de producción. Así, la política y la militancia de izquierda no se plantean como elementos externos a la cotidianeidad de la fábrica, sino que se imbrican y se construyen mutuamente.

Incluso, en este caso, podemos plantear la hipótesis de que lo que politiza los reclamos de los trabajadores no es sólo la influencia de militantes y activistas de izquierda, sino también la oposición que encuentran los reclamos de los trabajadores tanto por parte de la empresa como de la dirigencia sindical. Este elemento aparece explícitamente en el discurso de Daniel, donde se evidencia el mismo deslizamiento entre las demandas económicas y su militancia sindical y partidaria:

... yo ingresé en el 2005 a la fábrica, nosotros cobrábamos el sueldo más las horas extra, que eran casi como medio sueldo más, y unos tickets alimentarios (...) Yo me había ido a vivir a la casa de mi abuela, no tenía nada, y en ese momento me compré una bici, me compré una moto, después el auto, y me fui haciendo la casa arriba, le daba plata a mi abuela, le daba los tickets, o sea, estaba bien económicamente. Y por ahí lo que planteaba Gastón y nuestros compañeros me llegaba de costado. En ese momento tocaba la billetera y tenía plata. Entonces cuando se vino encima ese período del 2009, donde se sacaron los tickets (...) fue terrible, porque ahí incluso se vino, no sé si fue la segunda devaluación, o empezaron con todo a aumentar los precios...Y después ya lo que tenía ganado en ese momento, yo no lo quería perder, o sea, que me había comprado un autito, me había mudado arriba [de la casa de mi abuela] en ese momento, allá tenía todas mis cosas, esto que lo otro, y me empezaron a meter la mano en el bolsillo y entonces dije ¡No! esto no lo voy a permitir, y ya tenía el ámbito donde se desarrollaba 
todo eso, y bueno, ya directamente me empecé a sumar en las reuniones y a formar más parte...

Entrevista a Hernán y Daniel. Realizada el 3 de julio de 2015.

Más allá de las diferencias que motivan la decisión de organizarse en un caso y en otro, es interesante observar la importancia que asume la presencia de un ámbito concreto de organización, que logra articularse con las necesidades y demandas de los trabajadores. En ese sentido es que planteamos la centralidad que asume la organización independiente de los trabajadores en el lugar de trabajo en la politización de las relaciones de producción.

Pero la militancia no sólo es importante para explicar la manera en que se significan las demandas que surgen desde el terreno fabril, sino que también nos permite comprender cómo se significan las experiencias de lucha y cómo se trazan objetivos que superan las fronteras de la fábrica y los reclamos corporativos.

El conflicto de 2014 logró desarticular a la Lista Celeste. Los despidos alcanzaron a la mayoría de los delegados de la $\mathrm{CI}$, a los principales referentes del conflicto y de la lista opositora. Al momento de realizar las entrevistas sólo unos pocos trabajadores quedaban de aquella experiencia, la fábrica era dirigida por delegados oficialistas que habían sido designados por la dirección del sindicato, y las agresiones a los pocos trabajadores reincorporados eran cotidianas. Sin embargo, los sentidos que aquel conflicto imprimió en la tradición de lucha y de organización de la CI aún permanecían en la fábrica: la política se expresaba en gestos, en reconocimiento, en miradas, en respeto de aquellos que habían desafiado a la empresa y a la dirección del sindicato. Cuando le preguntamos a Daniel por qué seguía en la fábrica a pesar de las agresiones frecuentes que recibía por parte de la empresa y del sindicato, mencionó, además de su militancia, el reconocimiento que encontraba entre sus compañeros de trabajo:

Pregunta: Cuando te enfrentás a todo esto, ¿por qué lo hacés?

Daniel: Uno, por la militancia. La militancia que tengo, me ayuda mucho. No es personal. No es que soy yo contra esta patota, sino que tengo el peso atrás. No un peso malo, sino una espalda. Por ejemplo, ya viéndolo más políticamente, si los tipos me quebraban a mí, o por ejemplo quebraban a Hernán, yo no estaría ahí adentro. Si los tipos me quebraban a mí, no es posible que mis compañeros que están esperando puedan entrar (...) Y después el apoyo de los compañeros de adentro (...) Por ejemplo, levanto la cabeza, y uno allá me guiña el ojo, otro allá me guiña el ojo. Este, este y este, todos están conmigo, me hacen así [hace el gesto con el dedo pulgar para arriba]. 0 cuando pasan me hacen así [hace el gesto de una palmada en la espalda], o cuando voy al baño me dicen “¡capo!” [se ríe]. 0 los laburantes más viejos "buen provecho, "buen día". Por ejemplo, los tipos de la cocina me dan dos pizzas ¡Es re loco! Entrevista a Daniel. Realizada el 15 de julio de 2015.

En este punto del relato la política en la fábrica vuelve a cobrar visibilidad, al tiempo que adopta otras modalidades. El ataque por parte de la empresa y el sindicato contra los únicos tres referentes de la Lista Celeste que aún quedaban en la fábrica (que incluyó agresiones físicas y verbales) planteaba una relectura de las relaciones laborales y volvía a dejar en evidencia la articulación entre sindicalismo y política: luego del conflicto era 
necesario despolitizar la fábrica. Aunque la presencia de algunos de los referentes de aquella experiencia no planteara una articulación directa entre política, organización sindical y militancia, la política se expresaba en los gestos que Daniel identificaba entre sus compañeros como signo de reconocimiento y respeto de su militancia.

La manera en que se desarrolló el conflicto, su extensión y el modo en que la violencia cotidiana que envuelve los espacios de trabajo se agudizó en numerosas represiones dentro y fuera del espacio fabril, nos interrogan acerca de los límites de la política en la fábrica y las relaciones entre explotación, dominación, coerción y consenso que allí se desarrolla. En Lear, la intensificación de los ritmos de trabajo, la presencia de activistas de izquierda, y la intransigencia de la empresa y de los viejos dirigentes sindicales, son algunos de los elementos que contribuyen a explicar la permeabilidad de las "ideas de izquierda"; las continuidades entre lo sindical y lo político que observamos en el lugar de trabajo.

\section{Reflexiones finales}

Tanto para la empresa, como para el SMATA e incluso para el gobierno nacional, el conflicto de Lear del año 2014 fue un conflicto político. Los medios de comunicación también recuperaban esta caracterización, detrás de la que seguía la deslegitimación del reclamo. Se relacionaba lo político con intereses particulares de algunos partidos de izquierda (contrarios a los "intereses comunes" y, por ende, "externos" al lugar de trabajo), con la "radicalización ideológica" (cuyo objetivo sería mantener permanentemente el conflicto), con la apelación a la acción directa (en oposición a la negociación entre las partes). De este modo, se buscaba distinguir los conflictos válidos de aquellos que, como éste, no lo eran.

En este contexto, el análisis que planteamos en el artículo nos permitió problematizar qué significa la política en una fábrica hoy, qué sentidos involucra, y qué modalidades adopta; lo que implica volver (una vez más) a la pregunta por la relación entre sindicalismo y política.

Un primer elemento que observamos es que la política aparece con límites difusos en la fábrica, y que también se vincula con los modos de trabajar y de vivir por fuera de ella. En las conversaciones con los entrevistados no era posible mantener en ejes separados las condiciones de trabajo, luego el conflicto y más tarde la reflexión sobre la militancia y la influencia de la izquierda en la fábrica. Todos estos elementos aparecían entremezclados, junto con anécdotas personales, recuerdos y reflexiones. Estas maneras de narrar los hechos, se revelaron luego como lo más rico de las entrevistas para entender algunas de las vías a partir de las cuales se expresa la política en la fábrica. Los trabajadores no hacen política sólo cuando militan en un partido político o en el sindicato, sino también cuando se reúnen fuera de la fábrica para discutir sus problemas, cuando se solidarizan con sus compañeros de trabajo, cuando reconocen con pequeños gestos a quienes enfrentan las arbitrariedades de la patronal, y también en el modo en que trabajan. De este modo, observamos que detrás de estos límites difusos de la política, había en realidad un proceso de politización de las relaciones sociales que se desarrollaban en la fábrica. Como sostuvimos más arriba, la separación de la esfera económica y la esfera política en el capitalismo, hace que las relaciones de explotación sean leídas como relaciones económicas propias de los espacios privados de producción, mientras que los trabajadores hacen política, pero en el terreno público que se define fuera de la fábrica. Así, como señala Meiksins Wood, se terminan transformando las luchas por la apropiación en luchas aparentemente no políticas. 
Teniendo en cuenta esto, en el artículo no clasificamos las demandas en económicas o políticas, como si hubiera una frontera clara entre unas y otras, sino que buscamos dar cuenta de las continuidades que podíamos observar entre lo sindical y lo político, es decir, los procesos mediante los cuales las relaciones de producción eran significadas y entendidas como el resultado de luchas de clase y relaciones sociales de explotación.

En definitiva, lo que reconstruimos fue el proceso mediante el cual la separación entre sindicalismo y política empezaba a desarticularse, aunque solo sea momentáneamente, a partir de situaciones y/o condiciones particulares. Para ello, partimos de tres dimensiones de análisis que retomamos de la interpretación que propone Meiksins Wood acerca de esta división en el capitalismo, y ordenamos la discusión a partir de estos tres niveles. Un primer nivel, lo ubicamos en el momento en que la lucha de intereses en el terreno de la producción trascendía las fronteras de la fábrica. La intervención directa del Estado dejaba en evidencia la naturaleza política del reclamo por los despidos. Un segundo nivel, cuando la conflictividad intrafabril (por condiciones de trabajo y despidos) ponía en duda el pleno poder de decisión del capital sobre el proceso de trabajo. Allí, como señalamos, no solo era importante mirar el tipo de demandas, sino también la orientación y significación de los reclamos. Y el tercer nivel se relaciona precisamente con el modo en que dicha orientación actúa en el lugar de trabajo, particularmente con la intervención de organizaciones políticas. Si la intervención del Estado fue fundamental para develar el carácter político de las relaciones de producción, la intervención de la izquierda lo fue para significar los reclamos del lugar de trabajo en términos de clase, y reconstruir los vínculos entre el afuera y el adentro de la fábrica. En este caso vimos que se trataba de una militancia que no operaba "desde afuera" ni alejada de los trabajadores, sino que surgió y se fortaleció en la fábrica.

Teniendo en cuenta lo dicho hasta aquí, entendemos que calificar como político el accionar de los trabajadores, atribuyéndole una valoración negativa a partir de esa definición, implica la deslegitimación a una serie de prácticas que definen estrategias políticas particulares. No se trata de un cuestionamiento a la política en general, sino a determinadas estrategias políticas. Si, como vimos, la separación entre economía y política no busca más que prefigurar modos particulares de hacer política bajo el capitalismo, siempre alejada de ideologías anticapitalistas y del lugar de la explotación y la apropiación del plustrabajo, la

discusión sobre esta compleja relación no puede quedar ausente en los estudios sobre los sindicatos, en tanto se plantea como una vía de aproximación a la heterogeneidad que atraviesa a las organizaciones sindicales en la actualidad.

\section{Bibliografía}

Beaud, Stéphane y Pialoux, Michel, Repensar la condición obrera. Investigación en las fábricas de Peugeot de Sochaux-Montbéliard, Buenos Aires, Antropofagia, 2015.

Beaud, Stéphane ; Confavreux, Joseph y Lindgaard, Jade, La France Invisible, Paris, Éditions La Découverte/Poche, 2008.

Bourdieu, Pierre, La miseria del mundo, Buenos Aires, Fondo de Cultura Económica, 1999. 
Camarero, Hernán, A la conquista de la clase obrera. Los comunistas y el mundo del trabajo en la Argentina, 1920-1935. Buenos Aires, Siglo XXI, 2007.

Cambiasso, Mariela, Tradición de organización y estrategias sindicales. Un estudio sobre la organización sindical en la fábrica alimenticia Kraft-Mondelez (ex Terrabusi) en la postconvertibilidad, Tesis de Doctorado en Ciencias Sociales, UBA, 2015.

Ceruso, Diego, La izquierda en la fábrica. La militancia obrera industrial en el lugar de trabajo, 1916-1943, Buenos Aires, Imago Mundi, 2015.

Cohen, Sheila, "Left agency and class action: The paradox of workplace radicalism", Capital \& Class, vol. 35, nํㅜ, 2011.

Connolly, Heather y Darlington, Ralph, "Radical political unionism in France and Britain: A comparative study of SUD-Rail and the RMT", European Journal of Industrial Relations, 18(3), 2012.

Cotarelo, María Celia, "Movimiento sindical en argentina 2004-2007: ¿anarquía sindical?", XI Jornadas Interescuelas, San Miguel de Tucumán, Departamento de historia, Universidad Nacional de Tucumán, 2007.

D`Urso, Lucila y Longo, Julieta, “The radical political unionism as renewal strategy in Argentina”, Latin American Perspectives, 2017.

Duhalde, Santiago, La vida al interior del sindicato. Estudio de caso sobre la dinámica interna de la asociación trabajadores del estado, 2003-2008, Tesis de doctorado en co-tutela. Universidad de Buenos Aires - Universidad de Paris VIII - Vincennes-Saint-Denis, 2011.

Etchemendy Sebastián y Collier, Ruth Berins, "Golpeados pero de pie: Resurgimiento

Sindical y Neocorporativismo Segmentado en Argentina (2003-2007)”, publicado originalmente como "Down but not out: Union resurgence and segmented neocorporatism in Argentina (2003-2007)", en Politics and Society, vol. 35, no 3, 2008.

Figari, Claudia, "La pericia técnica como campo en disputa: estrategias de control empresarial en filiales de empresas transnacionales radicadas en Argentina", Revista Sociedad y Economía, 30, 2016

Frege, Carola y Kelly, John "Union Revitalization Strategies in Comparative Perspective”, European Journal of Industrial Relations, 9(1), 2003.

Gilly, Adolfo, "La anomalía argentina (Estado, Corporaciones y trabajadores)", en El estado en América Latina: teoría y práctica. México DF, Siglo XXI, 1990.

Kelly, John, Rehinking industrial relations. Mobilization, collectivism and long waves. London, Routledge, 1998.

Lenguita, Paula y Varela, Paula, "Una reflexión sobre el rol de las comisiones internas en el sindicalismo argentino", Figari, Claudia; Lenguita; Paula y Montes Cató, Juan (comp.), El movimiento obrero en disputa. La organización colectiva de los trabajadores, su lucha y resistencia en la Argentina del siglo XX, Buenos Aires, Ediciones Ciccus, 2010.

Lenguita, Paula, La política del teletrabajo. Un estudio comparativo sobre las ideologías y prácticas de control laboral destinadas a los teletrabajadores a domicilio en la Argentina, Tesis de Doctorado en Ciencias Sociales, UBA, 2006.

Longo, Julieta, ¿Renovación de las tradiciones sindicales en ámbitos laborales precarizados? Un análisis de las organizaciones sindicales en empresas supermercadistas durante la posconvertibilidad, Tesis de Doctorado en Ciencias Sociales, UBA, 2014.

Marticorena, Clara, "¿Sindicalismo de base vs. sindicalismo en la base? Un aporte al debate sobre revitalización sindical en Argentina a partir del análisis de la organización y 
dinámica sindical en el sector químico", VIII Congreso Latinoamericano de Estudios del Trabajo (ALAST), Buenos Aires, 2016.

Meiksins Wood, Ellen, "La separación de lo "económico" y lo "político" en el capitalismo", Ellen Meiksins Wood, Democracia contra capitalismo. México DF, Siglo XXI, 2000. Montes Cató, Juan, Dominación y resistencia en los espacios de trabajo. Estudio sobre las relaciones de trabajo en empresas de telecomunicaciones, Tesis de Doctorado en Ciencias Sociales, UBA, 2006.

Moody, Kim, "Towards an international social mouvement unionism". New Left Review, n. 225, 1998.

Pialoux, Michel y Corouge, Christian, Resister a la chaine. Dialogue entre un ouvrier de Peugeot et un sociologue. Marsella, Agone, 2011.

Pialoux, Michel, "Chronique Peugeot", Actes de la Recherche en Sciences Social, vol. 52/53, n 1, pp. 1984.

Santella, Agustín, Labor conflict and capitalist hegemony in Argentina. The case of the automobile industry, 1990-2007. Leiden-Boston: Brill, 2016.

Senén González, Cecilia y Haidar, Julieta, "Revitalización sindical en perspectiva comparada. Un aporte al análisis sectorial en Argentina”, Arturo Fernández y Cecilia Senén González, Cecilia (comps). Estado, instituciones laborales y acción sindical en países del MERCOSUR frente al contexto de la crisis mundial. Buenos Aires, Prometeo, 2009.

Smith, Vicky, "El legado de Braverman. La tradición del proceso de trabajo veinte años más tarde", Revista Sociología del Trabajo, Nueva Época, 26, España, 1995

Upchurch, Martín y Mathers, Andy, "Neoliberal Globalization and Trade Unionism: Toward Radical Political Unionism?”, Critical Sociology, 38(2), 2011.

Varela, Paula, “¿Revitalización sindical sin debate de estrategias?”, Paula Varela (Coord.) El gigante fragmentado. Trabajadores, sindicatos y política durante el kirchnerismo, Buenos Aires, Final abierto, 2016.

Varela, Paula, La disputa por la dignidad obrera. Sindicalismo de base fabril en la zona norte del Conurbano bonaerense 2003-2014, Buenos Aires, Imago Mundi-Colección Archivos, 2015.

Ventrici, Patricia, Sindicalismo de base en la Argentina contemporánea. El cuerpo de delegados del subterráneo, Tesis de Doctorado en Ciencias Sociales, UBA, 2011. 